\title{
A mutational analysis of spliceosome assembly: evidence for splice site collaboration during spliceosome formation
}

\author{
Angus I. Lamond, Maria M. Konarska, and Phillip A. Sharp \\ Center for Cancer Research and Department of Biology, Massachusetts Institute of Technology, Cambridge, Massachusetts \\ 02139 USA
}

\begin{abstract}
We have analyzed the pathway of mammalian spliceosome assembly in vitro using a mobility retardation assay. The binding of splicing complexes to both wild-type and mutant $\beta$-globin pre-RNAs was studied. Three kinetically related, ATP-dependent complexes, $\alpha, \beta$, and $\gamma$, were resolved with a wild-type $\beta$-globin substrate. These complexes formed, both temporally and in order of decreasing mobility, $\alpha \rightarrow \beta \rightarrow \gamma$. All three complexes contained U2 snRNA. The RNA intermediates of splicing, i.e., free $5^{\prime}$ exon and intron lariat $+3^{\prime}$ exon, were found predominantly in the $\gamma$ complex. The RNA products of splicing, i.e., ligated exons and fully excised intron lariat, were found in separate, postsplicing complexes which appeared to form via breakdown of $\gamma$. Mutations of the $5^{\prime}$ splice site, which caused an accumulation of splicing intermediates, also resulted in accumulation of the $\gamma$ complex. Mutations of the $3^{\prime}$ splice site, which severely inhibited splicing, reduced the efficiency and altered the pattern of complex formation. Surprisingly, the analysis of double mutants, with sequence alterations at both the $5^{\prime}$ and $3^{\prime}$ splice sites, revealed that the $5^{\prime}$ splice site genotype was important for the efficient formation of a U2 snRNA-containing $\alpha$ complex at the $3^{\prime}$ splice site. Thus, it appears that a collaborative interaction between the separate $5^{\prime}$ and $3^{\prime}$ splice sites promotes spliceosome assembly.
\end{abstract}

[Key Words: RNA splicing; mRNA precursors; spliceosome; ribonucleoprotein particles]

Received May 20, 1987; revised version accepted June 16, 1987.

Splicing of nuclear mRNA precursors (pre-RNA) involves the joining of two specific splice sites that can be widely separated, often by thousands of bases. The mechanism of splice site selection is poorly understood but must involve sequence recognition at both the $5^{\prime}$ and $3^{\prime}$ splice sites. Mutational studies have demonstrated the importance of the conserved sequences located at the intron-exon junctions of mammalian preRNAs, e.g., a comprehensive analysis has been made for a large collection of mutants in the large intron of rabbit $\beta$-globin (Aebi et al. 1986). This has shown that mutants with alterations in the highly conserved GU or AG dinucleotides, located, respectively, at the $5^{\prime}$ and $3^{\prime}$ splice sites, promote the utilization in vivo of previously inactive cryptic splice sites. In most cases the level of spliced RNA appearing in the cytoplasm is also reduced. When the same mutants were analyzed in vitro, they were found to be processed in two separate ways. This either generated spliced RNAs utilizing the same cryptic sites observed in vivo or caused an accumulation of the splicing intermediates, with the reaction arrested after the initial 5' cleavage event. Presumably these latter RNAs are degraded in vivo.

Small nuclear ribonucleoprotein particles (snRNPs) are an integral part of the nuclear splicing mechanism.
Specific degradation of snRNA sequences in any of the snRNPs U1, U2, U4, or U6 by treatment with RNase $\mathrm{H}$ and complementary deoxyoligonucleotides inactivates splicing in vitro (Krämer et al. 1984; Black et al. 1985; Krainer and Maniatis 1985; Berget and Robberson 1986; Black and Steitz 1986). Strong evidence suggests that the Ul snRNP recognizes sequences at the $5^{\prime}$ splice site through RNA-RNA complementarity (Zhuang and Weiner 1986). Another snRNP, U2, binds to sequences upstream of the $3^{\prime}$ splice site forming a very stable complex (Black et al. 1985; Konarska and Sharp 1986). This U2 snRNP-precursor RNA complex kinetically precedes the formation of a multicomponent spliceosome, which contains the intermediate RNAs in splicing, i.e., the lariat IVS-3' exon RNA and the $5^{\prime}$ exon RNA. The mature spliceosome contains, in addition to $\mathrm{U} 2$, at least three other snRNPs, U4, U5, and U6 (Grabowski and Sharp 1986; Konarska and Sharp 1987). Surprisingly, as purified, neither the initial U2 snRNP complex nor the complete spliceosome contains U1 snRNA, though the integrity of the Ul snRNP particle is essential for splicing.

Spliceosomes were first detected as 40-60S complexes by sedimentation velocity gradient analysis (Brody and Abelson 1985; Frendewey and Keller 1985; 
Grabowski et al. 1985; Perkins et al. 1986). Higher resolution of splicing complexes has been achieved by electrophoresis in native polyacrylamide gels (Konarska and Sharp 1986; Pikielny and Rosbash 1986; Pikielny et al. 1986). In most cases, either heparin or carrier RNA was added to the samples to suppress nonspecific binding of basic proteins. These conditions permitted the resolution of two complexes using nuclear extracts of mammalian cells (Konarska and Sharp 1986). The faster-migrating complex contained U2 snRNP bound to sequences upstream of the $3^{\prime}$ splice site. The slower complex corresponded to the spliceosome. Formation of the U2 snRNP-precursor RNA complex kinetically preceded that of the spliceosome. Recently, gel electrophoresis conditions were established which allow resolution of splicing complexes in the absence of added polyanions such as heparin or RNA. Under these conditions, many endogenous snRNP-snRNP complexes can be detected as well as splicing complexes (Konarska and Sharp 1987).

We report here an analysis of mammalian spliceosome assembly using a native gel mobility retardation assay. The interaction of splicing complexes with both wildtype and mutant $\beta$-globin pre-RNA substrates has been studied and these data point toward a stepwise pathway for spliceosome formation. Surprisingly, recognition of the $5^{\prime}$ splice site is shown to be important for formation of the U2 snRNP complex upstream of the 3' splice site even though this complex does not contain Ul snRNA.

\section{Results}

pre-RNA substrates

Wild-type pre-RNA substrate was synthesized by T3 RNA polymerase transcription of a DNA template (pBSAL4) that contained a deleted form of the second intron of rabbit $\beta$-globin (Fig. 1a). The intron was shortened by a deletion of the sequences between the HincII and 3'-proximal SspI sites. These deleted sequences have been shown not to influence either the efficiency or accuracy of globin mRNA splicing in vivo. Uniformly labeled pre-RNA (428 nucleotides) was prepared by transcribing EcoRI-digested pBSAL4. This pre-mRNA contained an intron of 319 nucleotides length and 5' and 3' exon lengths of 56 and 53 nucleotides, respectively. Figure $1 \mathrm{~b}$ shows the sequences of both the $5^{\prime}$ and $3^{\prime}$ exon-intron junctions. The natures of the point mutations, which are analyzed in Figures 3 and 4 (below), are indicated by arrows. Except for the specific point mutations, the structures of these mutant pre-RNAs are identical with that of the pre-RNA substrate made from

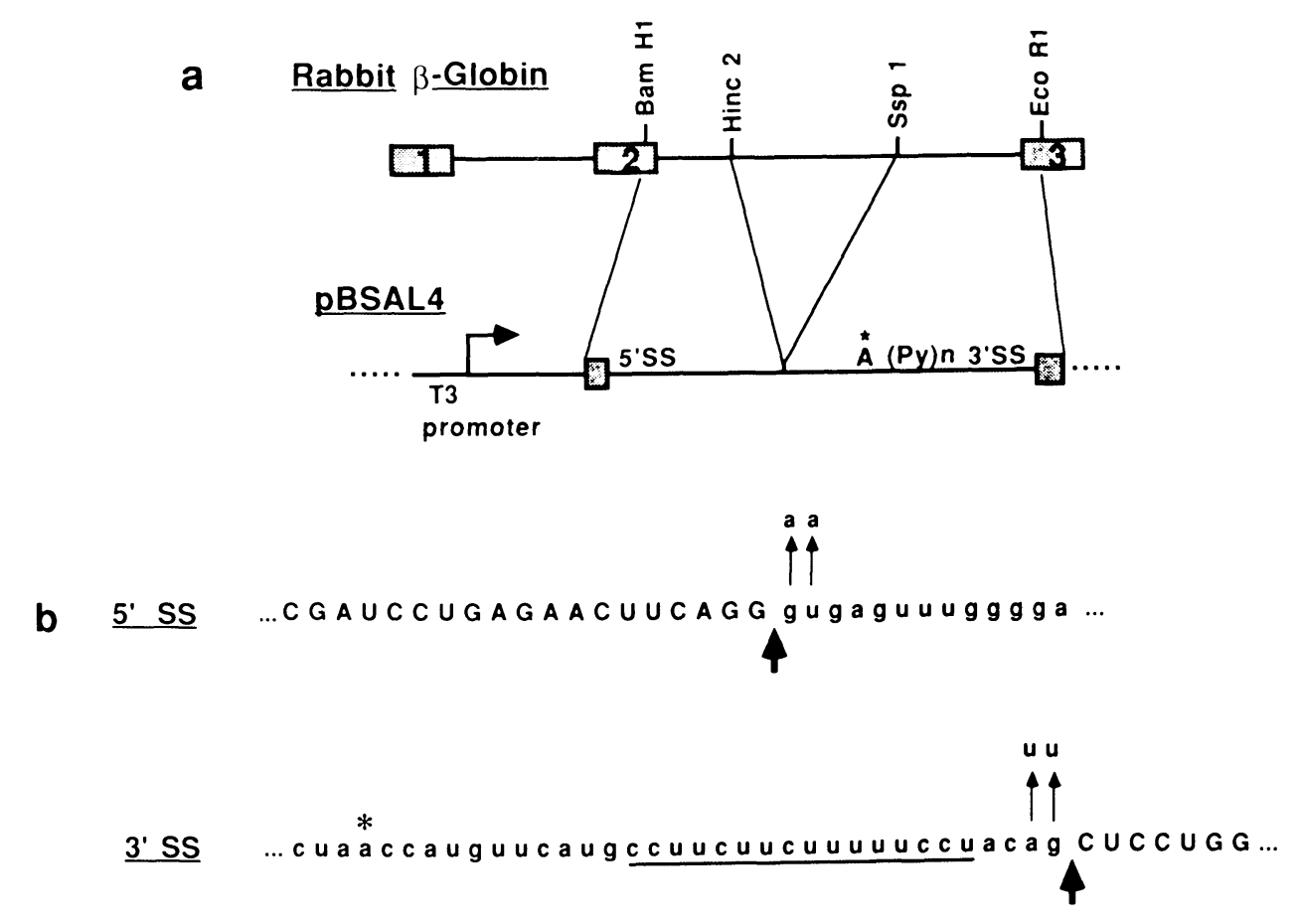

Figure 1. (a) Construction of pBSAL4. A plasmid template for the synthesis of $\beta$-globin pre-RNA was made by way of a three-way ligation between the BamHI-HincII and SspI-EcoRI fragments of the rabbit $\beta$-globin gene and the pBluescript vector that was cleaved in the polylinker at both the BamHI and EcoRI sites. The resulting construct, pBSAL4, is wild type for both the $5^{\prime}$ and $3^{\prime}$ splice sites but has had 254 nucleotides of internal intron sequences deleted. Globin exon sequences are shaded. Continuously labeled pre-RNA was made by in vitro transcription of EcoRI-cut pBSAL4 with T3 RNA polymerase. $(b)$ The nucleotide sequences of both the 5' and 3' intron-exon junctions are shown for the wild-type $\beta$-globin pre-RNA substrate. Exon sequences are in upper case and intron sequences in lower case. Arrowheads mark the cleavage sites at each splice site, the branch acceptor is shown with an asterisk and the polypyrimidine tract at the $3^{\prime}$ splice site is underlined. The location and genotypes of the point mutations analyzed in Figs. 3,4 , and 5 are shown by vertical arrows. Plasmids carrying mutant pre-RNA sequences downstream of the T3 promoter were constructed by an identical strategy to that described above for pBSAL4, using the mutant globin plasmids described by Aebi et al. (1986). 
pBSAL4 (Fig. 1a). A 5' deletion mutant was made by subcloning the $S s p I-E c o R I$ fragment, containing the wildtype $\beta$-globin 3' splice site (Fig. la), between the HincII and EcoRI sites of the pBluescript vector. The resulting plasmid, pBSALl, was then cut with EcoRI and pre-RNA made by in vitro transcription with T3 RNA polymerase.

\section{RNA splicing and complex formation}

The kinetics of both splicing and complex formation were analyzed in parallel (Fig. 2). As anticipated from previous work, the intermediate RNAs in splicing, i.e., the $5^{\prime}$ exon and lariat intron-3' exon, appear after a lag of approximately $30 \mathrm{~min}$. The initial lag represents the time required for the pre-RNA to associate with the

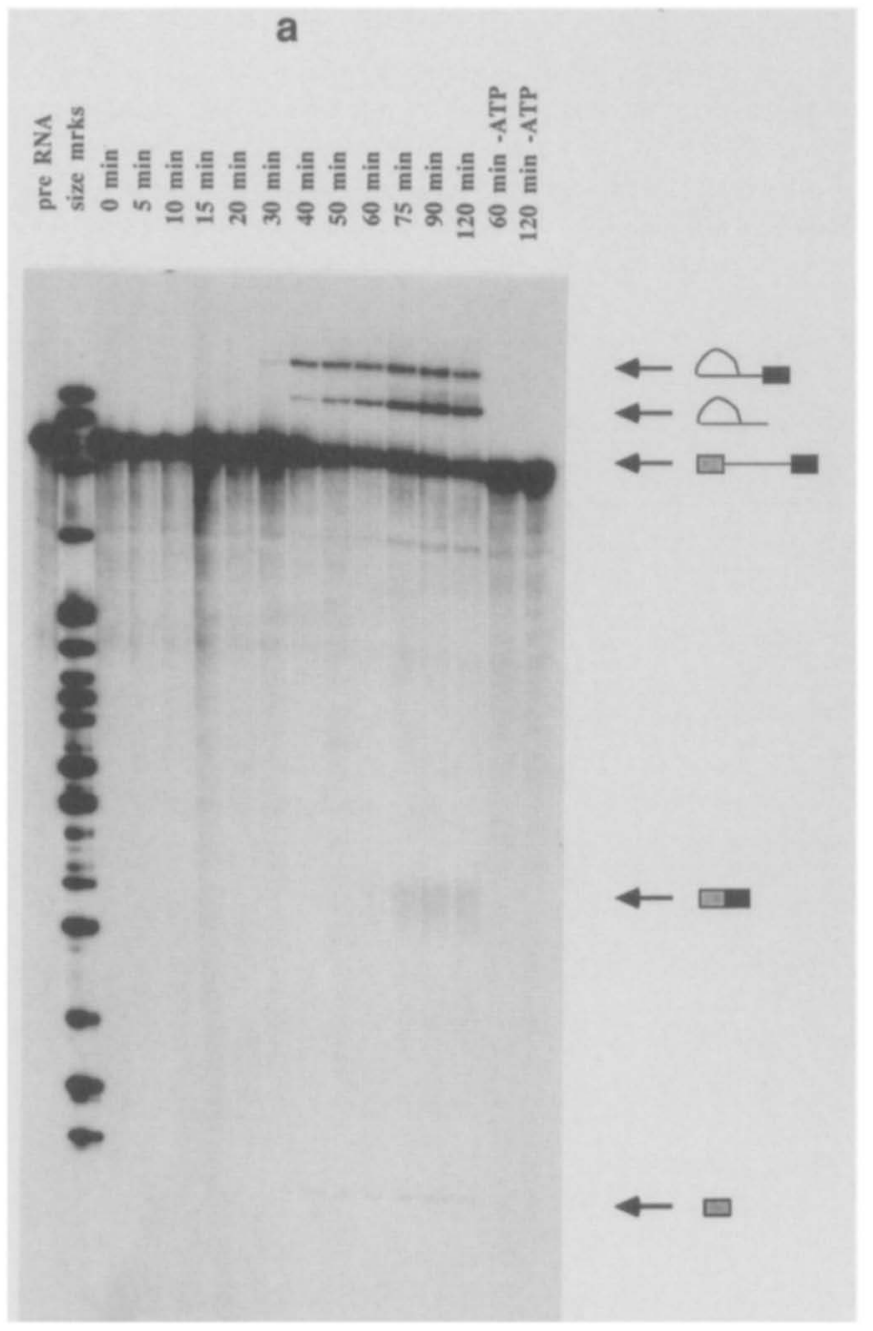

components of the splicing apparatus. At later times, these intermediate species are converted into splicing products, i.e., ligated exons and the lariat form of the fully excised intron (Fig. 2a). As shown, the splicing of pre-RNA in vitro is an ATP-dependent process. Aliquots from the same samples were also assayed for the formation of splicing complexes by native gel electrophoresis (Fig. 2b). Several points emerge from the kinetics of complex formation. Almost instantaneously, the preRNA is formed into a heterogeneous set of complexes that we collectively refer to as "sigma" complexes. These sigma complexes are significantly retarded in mobility relative to the free pre-RNA. The rapid formation of sigma complexes proceeds at $0^{\circ} \mathrm{C}$ and in the absence of ATP. Similar complexes also form on bacterial RNA sequences that are not known to contain introns (Konarska and Sharp 1986). Thus, the formation of sigma complexes is not splicing specific, although it is likely that these complexes can act as substrates for the subsequent binding of splicing-specific factors.

Figure 2 shows that during the $30-\mathrm{min}$ lag period preceding pre-RNA cleavage, the substrate is assembled into three, separable ATP-dependent complexes, termed $\alpha, \beta$, and $\gamma$. These complexes were formed in a kinetic order consistent with the order of decreasing mobility, $\alpha \rightarrow \beta \rightarrow \gamma$. The $\alpha$ complex was detectable after only 2 min of incubation while the $\beta$ complex appeared at 10

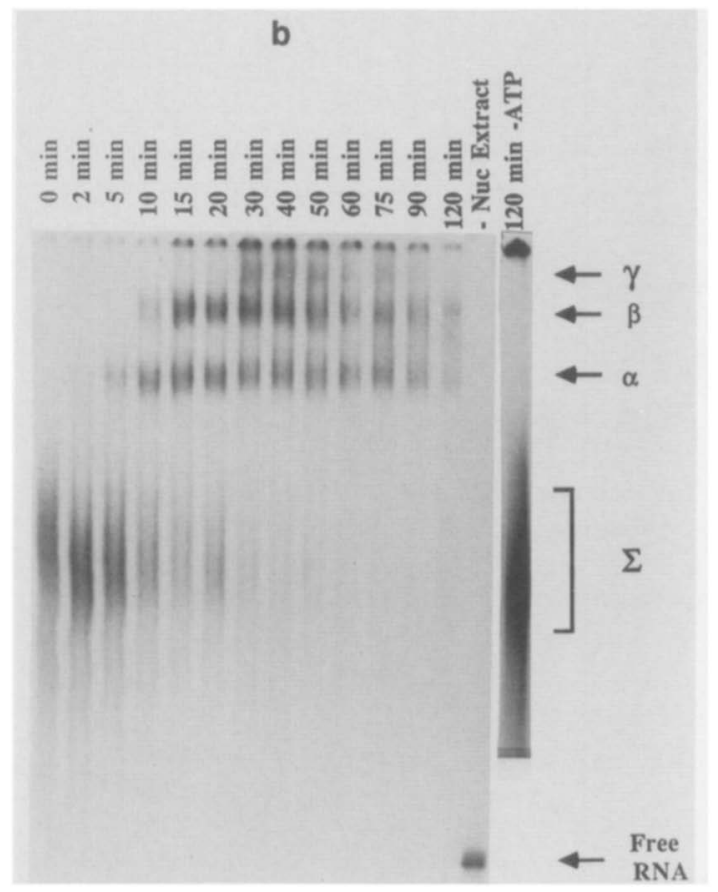

Figure 2. (a) Kinetics of splicing for the wild-type $\beta$-globin pre-RNA. The time course is from 0 to 2 hr. Annotations show the $5^{\prime}$ exon as a shaded box and the $3^{\prime}$ exon as a filled box. The abundance of the free $5^{\prime}$ exon and spliced exons is visually underestimated as these species are small and the RNAs are continuously labeled. Heterogeneity at the $3^{\prime}$ end of the pre-RNA, caused by staggered termination by T3 RNA polymerase at the EcoRI terminus of the DNA template, is responsible for the cluster of four to five bands seen in the position of the spliced exons. Size markers used here and on the other denaturing gels are MspI fragments of pBR322, end-labeled with [32 P]dCTP. $(b)$ Kinetics of complex formation for wild-type $\beta$-globin pre-RNA. Twenty-five percent of each of the samples analyzed for RNA splicing in $a$ was loaded onto a native polyacrylamide gel. The zero time point represents a time of $<10$ sec between adding the pre-RNA to nuclear extract and loading it onto the gel. 
min. The appearance of the $\gamma$ band, at $30 \mathrm{~min}$, coincided with the time when pre-RNA cleavage was first detected (see Fig. 2). Accumulation of the $\gamma$ complex continued from this point until later times when it decreased in proportion to other species. These kinetics suggest that $\gamma$ represents the spliceosome. We note that a small accumulation of radioactivity at the origin of the gel occurred with kinetics almost identical to those of $\gamma$ formation. Interestingly, the material sticking at the origin also decreased at later times, in parallel with the disappearance of $\gamma$. We have so far been unsuccessful in determining its composition. It may represent the nonspecific aggregation of $\beta$ - and $\gamma$-type complexes or, alternatively, a higher-order form of spliceosome structure. The parallel between the formation of the $\gamma$ band and RNA splicing is further underlined by a titration of magnesium chloride concentration. Splicing in vitro requires divalent cations. In this assay system the optimum magnesium chloride concentration was approximately 3 $\mathrm{mM}$, while concentrations of less than $1 \mathrm{~mm}$ or greater than $5 \mathrm{~mm}$ magnesium chloride severely inhibited splicing. The optimum magnesium chloride concentration for $\gamma$-complex formation was also seen at approximately $3 \mathrm{~mm}$ and at either high or low magnesium concentrations, where splicing was inhibited, $\gamma$ was not detected (data not shown).

\section{5 ' splice site mutations}

The dependence of complex formation on sequences at the $5^{\prime}$ and $3^{\prime}$ splice sites was tested. Certain point mutations of the highly conserved GU dinucleotide at the 5' splice site have been shown to inhibit splicing by blocking the second step of the reaction, i.e., the conversion of RNA intermediates to products (Newman et al. 1985; Parker and Guthrie 1985; Reed and Maniatis 1985; Aebi et al. 1986). Thus, these mutations still allow accurate $5^{\prime}$ cleavage, but totally inhibit subsequent cleavage and ligation at the $3^{\prime}$ splice site. The kinetics of both splicing and complex formation of the two $5^{\prime}$ splice site mutations shown in Figure $1 b$ have been analyzed. The two mutations gave essentially identical results and a set of data for one mutant, $\mathrm{G} \rightarrow \mathrm{A}$, is shown in Figure 3, $a$ and $b$. As expected, analysis of splicing of the $G \rightarrow A$ substrate showed that the RNA intermediates were blocked from conversion to products and accumulated with time. An additional phenotype was apparent from this kinetic analysis; the rate of $5^{\prime}$ exon cleavage was markedly reduced compared with wild-type (cf. Figs. 2a and 3a). These splicing phenotypes are consistent with the effects of the mutations on the formation of splicing complexes (Fig. 3b). The kinetics of formation and accumulation of the $\gamma$ band were one and the same as those of the splicing intermediates. In contrast to the situation with the wild-type substrate, the $\gamma$ complex continued to accumulate throughout incubation. Comparison of the kinetics of complex formation by wild-type and $\mathrm{G} \rightarrow$ A mutant substrates also showed that the rate of $\gamma$ formation was slower in the mutant case. The primary effect was a reduction in the rate of $\alpha$ formation with the mutant substrate, after which the $\beta$ and $\gamma$ bands formed quite rapidly. This implies that the formation of $\gamma$ is affected by the genotype of the $5^{\prime}$ splice site and that its formation represents a rate-limiting step during spliceosome assembly.

The assembly of complexes was also examined on a deleted RNA substrate that contained the wild-type 3' splice site and branch site sequences, but was lacking the $5^{\prime}$ splice site region, including the wild-type $5^{\prime}$ cleavage site and the two major cryptic cleavage sites. Surprisingly, this truncated RNA also formed three bands, $\alpha^{\prime \prime}, \beta^{\prime \prime}$, and $\gamma^{\prime \prime}$, with kinetics very similar to that of the $5^{\prime}$ point mutants previously described (Fig. 3d). Once again, the major effect on kinetics was a reduction in the rate of formation of $\alpha^{\prime \prime}$, supporting the contention that the formation of this complex is normally enhanced by recognition of the wild-type $5^{\prime}$ splice site. All the complexes formed with the $5^{\prime}$ splice site deletion mutant RNA migrated faster than the corresponding ones formed on the wild-type precursor. This is at least partly, and may be entirely, due to the reduced length of the deleted pre-RNA (A.I. Lamond, unpubl.). Whether these $\alpha^{\prime \prime}, \beta^{\prime \prime}$, and $\gamma^{\prime \prime}$ bands are identical in composition and structure to those formed on a wild-type substrate, however, remains to be established. A careful analysis of the RNA products from a splicing reaction revealed that the $5^{\prime}$ deletion mutant substrate will promiscuously form lariats, at very low levels, utilizing a cluster of novel cryptic 5' splice sites (data not shown). It is therefore difficult to assess whether spliceosome formation can actually proceed in the total absence of a functional $5^{\prime}$ splice site, or whether some weak form of $5^{\prime}$ interaction is necessary to promote assembly.

In contrast with the observed binding of complexes to a RNA containing only the $3^{\prime}$ splice site region, no specific complex formation was observed using a $\beta$-globin pre-RNA that contained only the wild-type 5 ' splice site region. Assays performed without ATP, or with mutant 5 ' splice site sequences, similarly showed no sign of specific complex formation in the absence of a $3^{\prime}$ splice site (data not shown).

\section{3' splice site mutations}

The phenotypes of two separate point mutations at the 3 ' splice site (cf. Fig. lb), have been assessed with respect to both splicing and complex formation. The data for one mutant, $3^{\prime} \mathrm{A} \rightarrow \mathrm{U}$, are presented. The $3^{\prime} \mathrm{G} \rightarrow \mathrm{U}$ mutant gives an identical result. In agreement with previous studies (Aebi et al. 1986), this 3' $\mathrm{A} \rightarrow \mathrm{U}$ mutation severely inhibits splicing in vitro (Fig. 3a). Only trace amounts of RNA intermediates, and no fully spliced products, were detected, even after long periods of incubation. A correspondingly dramatic inhibition of spliceosome assembly was observed with the native gel electrophoresis assay (Fig. 3c). Even at the longest times of incubation, only a small fraction of the pre-RNA was assembled into ATP-dependent complexes, the rest remained in the sigma region. While three separate ATPdependent bands were formed, their relative mobilities differed from those formed on the wild-type substrate (data not shown). These bands are labeled in order of de- 


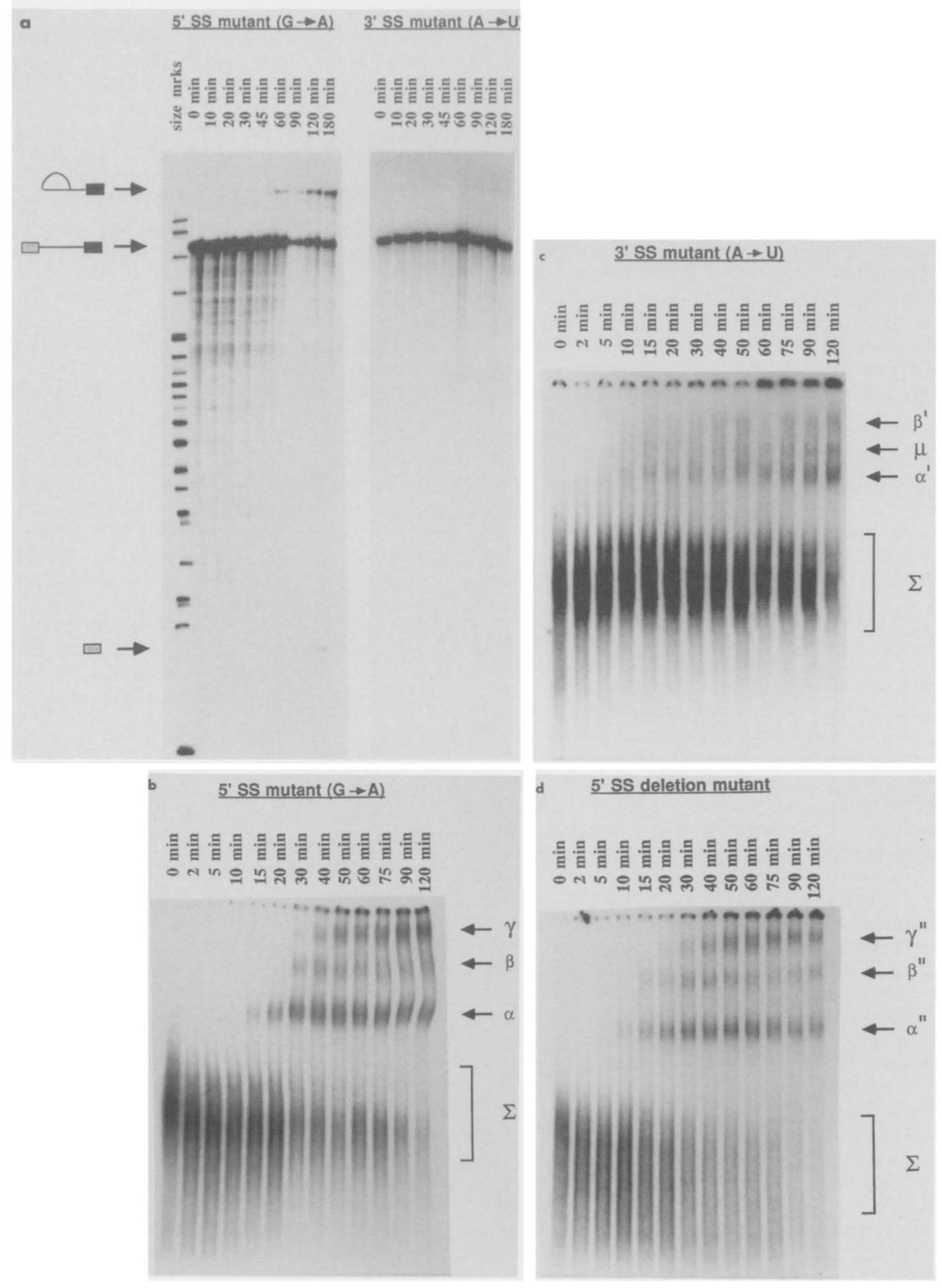

Figure 3. (a) Kinetics of splicing for mutant pre-RNAs. The $5^{\prime}$ point mutant $G \rightarrow A$ and $3^{\prime}$ point mutant $A \rightarrow U$ (cf. Fig. $1 b$ ) were assayed for splicing activity in vitro over a 3 -hr time course. $(b, c)$ Kinetics of complex formation for the $5^{\prime}$ and $3^{\prime}$ point mutant pre-RNAs assayed in $a$. (d) Kinetics of complex formation for a pre-RNA which has had the $5^{\prime}$ splice site deleted. 
creasing mobility as $\alpha^{\prime}, \mu$, and $\beta^{\prime}$. Bands $\alpha^{\prime}$ and $\beta^{\prime}$ approximately comigrate with the $\alpha$ and $\beta$ bands formed on either the wild-type or $5^{\prime}$ point mutant substrates. By contrast, the $\mu$ band clearly migrates in a novel position and its formation appears to be specific for pre-RNAs with mutations at the 3 ' splice site.

Figure $3 \mathrm{c}$ shows that both the rate and the quantity of $\alpha$-type complex formation with the 3 ' point mutant substrate is sharply curtailed relative to $\alpha$ complex formation with the wild-type substrate (Fig. 2b). Thus, again, it appears that a major rate-limiting step is the formation of this faster-migrating, ATP-dependent complex and that recognition of the $3^{\prime}$ splice site plays a quantitatively greater role in the formation of splicing complexes than does recognition of the $5^{\prime}$ splice site. The small quantity of splicing intermediates generated with substrates containing mutations at the $3^{\prime}$ splice site could be due to either a fully formed spliceosome that was present at such a low abundance that it was not detected here, or, alternatively, to the inefficient activity of an aberrant complex migrating in the $\mu$ or $\beta^{\prime}$ bands.

The novel species, $\mu$, may correspond to an authentic intermediate in the pathway of spliceosome formation which, in the presence of a wild-type $3^{\prime}$ splice site, is rapidly converted to another form (e.g., $\beta$ or $\gamma$ ) and is therefore not detectable. Alternatively, the $\mu$ band may be a completely aberrant complex that only arises when the normal binding reaction is perturbed by a mutation at the $3^{\prime}$ splice site.

\section{Distribution of pre-RNA species between complexes}

Both kinetic analysis and the phenotypes of mutant RNAs suggest that the $\gamma$ complex corresponds to the spliceosome and that the $\alpha$ complex is a precursor to the spliceosome. To probe further the relationships between the various forms of complexes detected by the mobility retardation assay, the distribution of radioactive preRNA species migrating in the vicinity of the complexes was analyzed. After incubation with uniformly labeled substrate RNA, a standard reaction was resolved on a native polyacrylamide gel and then RNA eluted from each section of the gel was resolved on a second denaturing polyacrylamide gel which contained $8 \mathrm{M}$ urea. The distribution of RNA species from a wild-type substrate was assayed after both short and long incubation times (Fig. $4 \mathrm{a}, \mathrm{b}$ ). The results clearly show that the intermediates and products of the splicing reaction partitioned across the native gel in a specific pattern. Unreacted pre-RNA was found in varying amounts in all positions of the gel, indicating its location in multiple types of complexes. In particular, it shows that intact pre-RNA can be assembled into complexes migrating at $\alpha, \beta$, and $\gamma$ mobilities. The intermediates of splicing, i.e., the $5^{\prime}$ exon and lariat intron $-3^{\prime}$ exon, comigrated toward the top of the gel at the position of the $\gamma$ band. The fact that both intermediate species precisely co-peak strongly suggests that they are part of a complex, i.e., the spliceosome.

The location of the splicing intermediates in the $\gamma$ band is further demonstrated by an analysis of the distri- bution of RNA species formed by the $5^{\prime}$ point mutant substrate $\left(5^{\prime} \mathrm{G} \rightarrow \mathrm{A}\right)$. The splicing of this mutant RNA results in the accumulation of both the intermediate RNAs and the $\gamma$ band (Fig. 3a,b). The distribution of RNAs across the native gel (Fig. 4c) shows that the intermediate species formed with the $5^{\prime}$ point mutant substrate again co-peak at a mobility coincident with the $\gamma$ band. We, therefore, conclude that a splicing complex, which migrates at the position of the $\gamma$ band, contains the RNA intermediates of the splicing reaction and may be responsible for generating them.

In contrast with the two intermediate species, the two products of splicing, i.e., the spliced exons and the fully excised intron lariat, did not comigrate in the native gel (Fig. 4a,b). Rather, the RNA products migrated in separate positions, neither of which coincided with the $\alpha, \beta$, or $\gamma$ bands that form prior to cleavage of the pre-RNA. A potentially important exception is that a small amount of the excised intron is apparently enriched in the $\gamma$ band. This suggests that, upon completion of splicing, the spliceosome breaks down in a specific way, releasing at least two types of postsplicing complexes that contain the separate reaction products. A large particle, with an apparent mobility intermediate between $\alpha$ and $\beta$, retains the excised intron lariat. A smaller complex, containing the spliced exons, migrates with a similar mobility to the sigma complexes. Possibly the bulk of the spliceosome remains in the larger complex with the excised intron. The position of migration of the spliced exons indicates that they are not present simply as free RNA. However, the heterogeneity of their position of migration is redolent of the rapidly formed sigma complexes and may indicate that they are associated with the same types of factors. It should also be noted that the particles containing the spliced exons migrate sufficiently rapidly that they have run off the bottom of most of the native gels shown.

\section{Collaboration between $5^{\prime}$ and 3' splice sites}

As noted above, the rate of formation of the initial $\alpha$ complex is reduced by mutations at the $5^{\prime}$ splice site. To investigate the possibility that recognition of the $5^{\prime}$ splice site was important for formation of $\alpha$, we tested a series of pre-RNA substrates with combinations of wildtype and mutant genotypes at both the $5^{\prime}$ and 3 ' splice sites, for activity in formation of complexes (Fig. 5). In each case where the substrate RNA contained a wildtype $3^{\prime}$ splice site, three ATP-dependent bands were formed (Fig. 5, lanes a). However, when the $3^{\prime}$ splice site was mutated to either of the point mutations $\mathrm{A} \rightarrow \mathrm{U}$ or $\mathrm{G} \rightarrow \mathrm{U}$ (cf. Fig. $1 \mathrm{~b}$ ), then both the pattern and efficiency of complex formation was influenced dramatically by the genotype of the cognate $5^{\prime}$ splice site (Fig. 5, b and c lanes). A significantly larger amount of complex formation was observed when the $3^{\prime}$ mutants were combined with a wild-type $5^{\prime}$ splice site than when they were combined with $5^{\prime}$ splice sites that carry either of the point mutants $G \rightarrow A$, or $U \rightarrow A$ (cf. Fig. 1b). If the $3^{\prime}$ mutants were combined with a deletion of the $5^{\prime}$ splice 
Lamond et al.
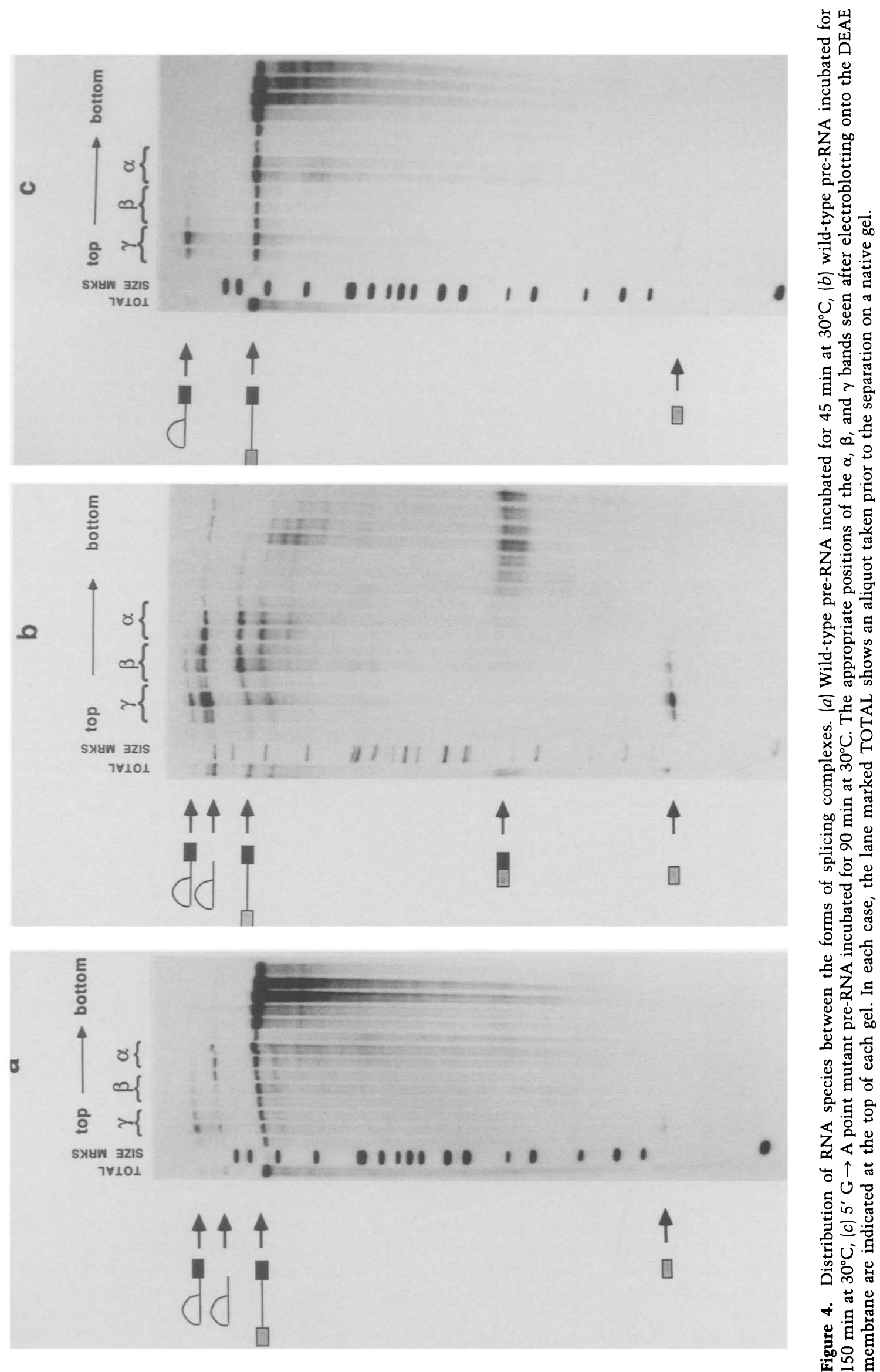


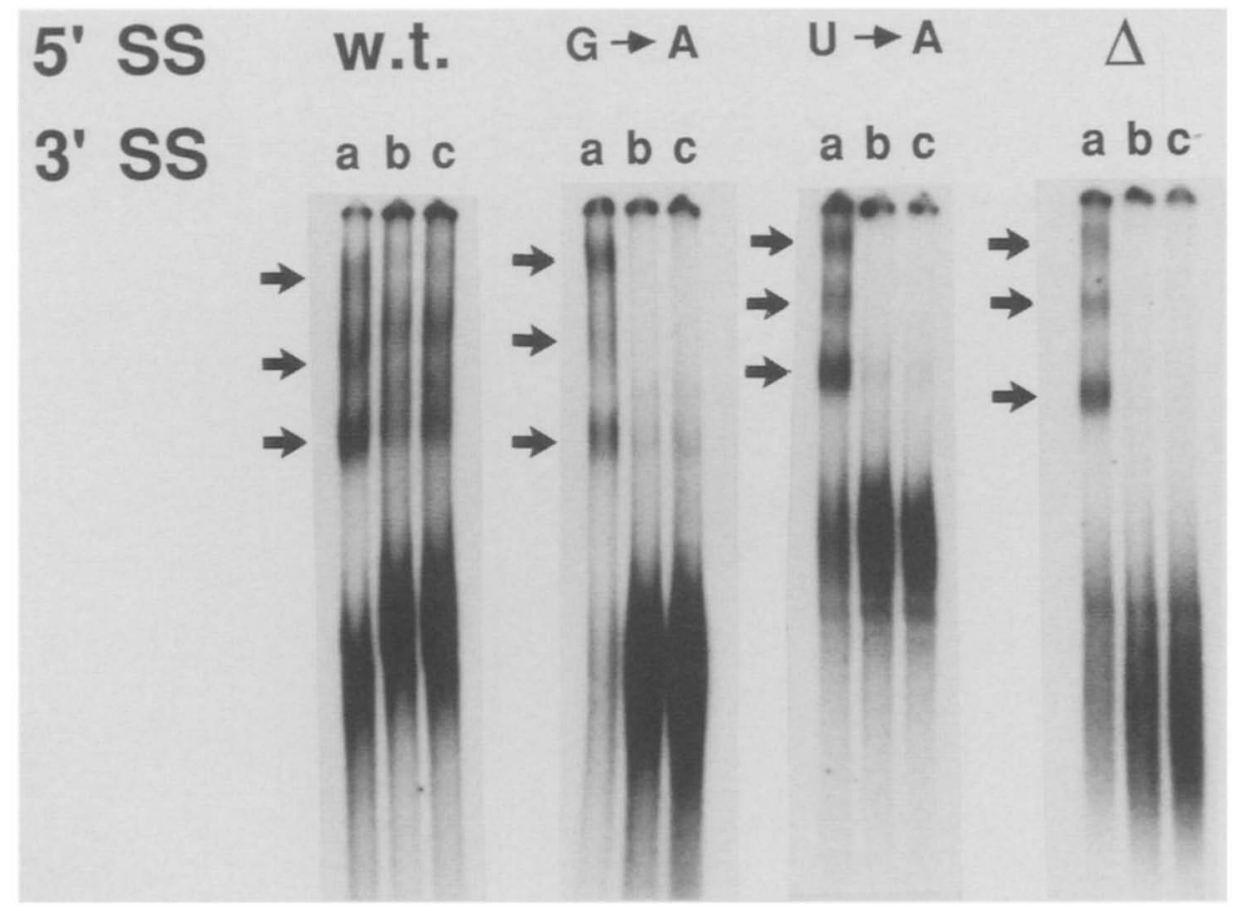

Figure 5. Complex formation with combinations of $5^{\prime}$ and $3^{\prime}$ splice site mutations on the pre-RNA substrates. In each of the four panels, which correspond to alternative $5^{\prime}$ splice site genotypes, the $3^{\prime}$ splice site is genotypically either wild type $(a), 3^{\prime} \mathrm{A} \rightarrow \mathrm{U}(b)$, or $3^{\prime} \mathrm{G} \rightarrow \mathrm{U}(c)$. The positions of the mutated nucleotides in the pre-RNA are those indicated in Fig. $1 \mathrm{~b}$. All the pre-RNAs were incubated in nuclear extract for $90 \mathrm{~min}$ at $30^{\circ} \mathrm{C}$, except for the fully wild-type pre-RNA ( $5^{\prime}$ SS wild type, lane $a$ ), which was incubated for only $45 \mathrm{~min}$ at $30^{\circ} \mathrm{C}$. In each panel, arrowheads indicate the location of the ATP-dependent splicing complexes formed in the presence of a wild-type $3^{\prime}$ splice site. The degree of separation between the complexes is not uniform as each panel is taken from a separate native gel.

site (analyzed in Fig. 3d), then no complex formation was detectable (Fig. 5).

These data, in combination with the studies of kinetics presented in Figure 3, argue strongly that formation of the $\alpha$ complex is facilitated by recognition of both the $5^{\prime}$ and $3^{\prime}$ splice sites. They also argue that the quantitative contributions of the separate splice sites are not equivalent. Rather, the genotype of the $3^{\prime}$ splice site is crucial for productive formation of $\alpha$, whereas the $5^{\prime}$ splice site genotype is by comparison only important.

\section{a Complex contains U2 snRNA}

Previous studies using the first intron of the adenovirus major late transcript showed that spliceosome assembly was preceded by the formation of an ATP-dependent pre-spliceosome complex, which contained U2 as its only snRNA component (Grabowski and Sharp 1986; Konarska and Sharp 1986). The U2 snRNP was bound to sequences upstream of the $3^{\prime}$ splice site. The snRNA composition of the $\alpha$ complex formed on both wild-type and mutant $\beta$-globin pre-RNA substrates was therefore investigated by Northern blotting to determine whether $\alpha$ corresponds to the same U2 snRNP complex.

As shown in Figure 6, all the ATP-dependent bands that were recognized by a probe complementary to the $\beta$-globin pre-RNA were also recognized by a probe complementary to U2 snRNA. By contrast, none of the complexes is recognized by a probe complementary to $\mathrm{U} 1$
snRNA. Thus, we conclude that the pre-spliceosome $\alpha$ type complexes that form on wild-type and mutant $\beta$ globin pre-RNAs are all U2 snRNA-containing complexes similar to that previously described with an adenovirus pre-RNA substrate. Additional experiments, to be reported elsewhere, further show that all of the $\alpha$-type complexes contain only U2 snRNA and none of the other abundant snRNAs, i.e., U4, U5, and U6, which have been shown to be stable components of the mature spliceosome (Lamond et al., in prep.). This is consistent with $\alpha$ being an intermediate in a stepwise pathway of spliceosome formation.

\section{Discussion}

The interaction of cellular components with both wildtype and mutant pre-RNA substrates in the formation of splicing complexes has been analyzed by means of a mobility retardation assay. The pre-RNA was sequentially assembled into three, separable, ATP-dependent complexes that were resolved as bands $\alpha, \beta$, and $\gamma$. The temporal order of appearance of these complexes corresponded to their rate of migration; $\alpha$ appeared first and migrated fastest while $\gamma$ appeared last and migrated slowest. The appearance of $\gamma$ coincided with cleavage of pre-RNA at the $5^{\prime}$ splice site which generates the splicing intermediates, i.e., $5^{\prime}$ exon and intron lariat $-3^{\prime}$ exon. In addition, both of these intermediate species were also found in the $\gamma$ band. The independent criteria 


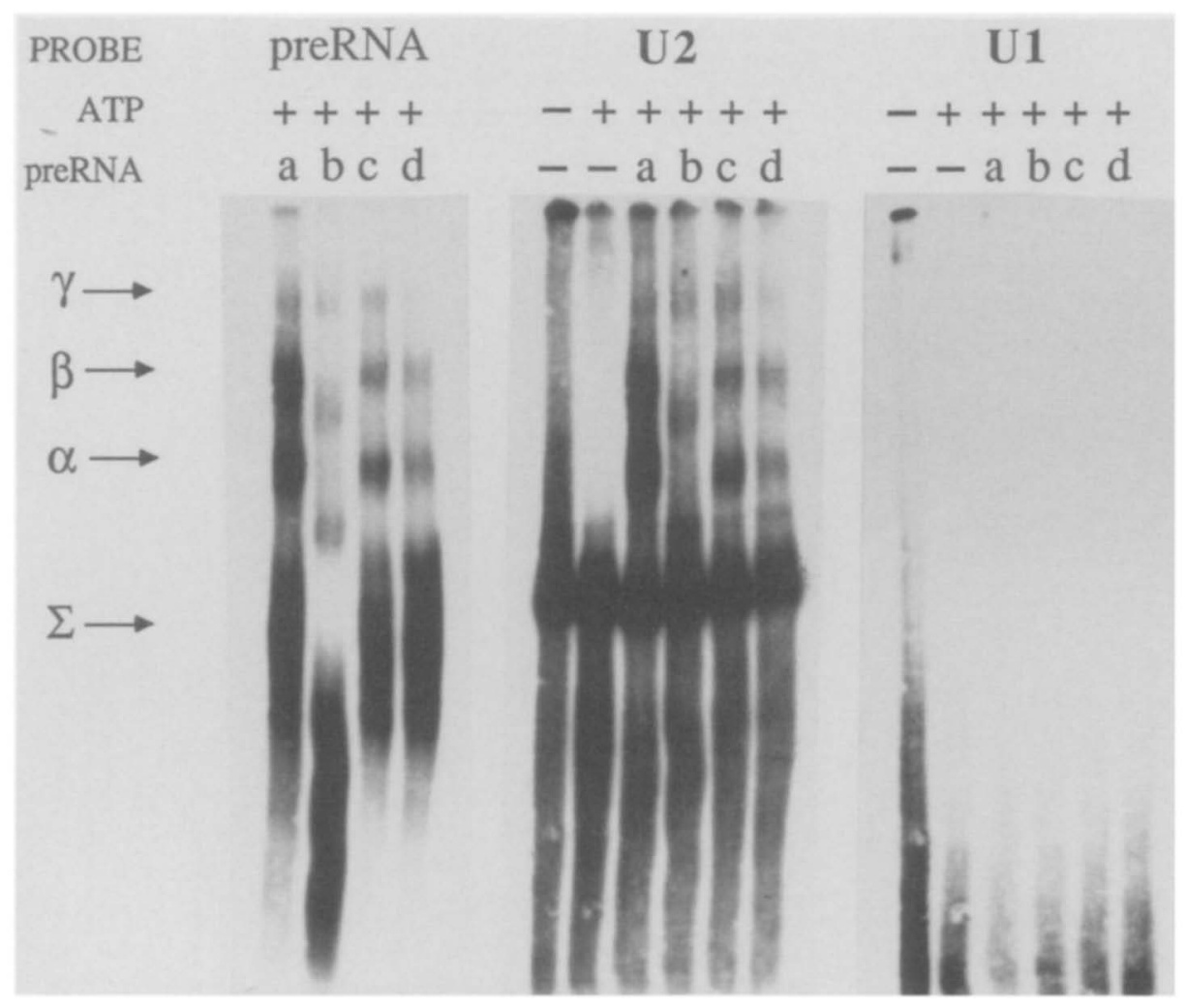

Figure 6. Northern blot analysis of snRNAs present in complexes formed on wild-type and mutant $\beta$-globin pre-RNAs. Unlabeled pre-RNAs-wild type $(a), 5^{\prime} \Delta(b), 5^{\prime} \mathrm{G} \rightarrow \mathrm{A}(c)$, and 3' $\mathrm{A} \rightarrow \mathrm{U}(\mathrm{d})$ (cf. Fig. lb), were incubated in nuclear extract under splicing conditions, separated on a native polyacrylamide gel, and blotted as described by Konarska and Sharp (1986). The same blot was then probed sequentially with ${ }^{32}$ P-labeled antisense $\beta$-globin pre-RNA, antisense U2, and antisense U1 snRNAs. Nuclear extract was also assayed, $(+)$ and $(-)$ ATP, in the absence of exogenous pre-RNA as a negative control.

of (1) $\gamma$ formation directly correlating with splicing activity for both kinetics and reaction conditions (Fig. 2), (2) $\gamma$ being affected by specific point mutations that block splicing (Fig. 3), and (3) the presence of both RNA species of the reaction intermediates in $\gamma$ (Fig. 4), suggest that an active form of the spliceosome migrates in the position of the $\gamma$ band.

At later times in the reaction, as the RNA intermediates are converted to products, $\gamma$ breaks down and the reaction products, i.e., spliced exons and intron lariat, partition between two separate types of postsplicing complexes. The larger form of the postsplicing complex retains the fully excised lariat intron, while the spliced exons appear to be associated with a small, or rapidly migrating, sort of particle. The potential location of the excised intron lariat in a postsplicing complex was previously indicated by the observation that the lariat is largely resistant to debranching, even though the nuclear extract contains an effective debranching activity that rapidly hydrolyzes the $2^{\prime}-5^{\prime}$ phosphodiester bond at the branch site of exogenously added, branched substrates (Ruskin and Green 1985a). In agreement with these data, the excised intron of an adenovirus-derived pre-RNA has similarly been shown to be associated with a large, postsplicing complex (Konarska and Sharp 1987). It will also be of great interest to identify the composition of the postsplicing particles that contain the spliced exons. Potentially, the presence of a specific set of com- ponents, perhaps derived in whole or in part from the spliceosome, could influence the subsequent fate of the bound RNA, e.g., by designating it for export from the nucleus.

The most speculative aspect of the scheme outlined in Figure 7 is the implied precursor-product relationship between the various forms of complexes. This is the most obvious relationship, but the present data certainly cannot exclude that one or more of these complexes results from an interaction that is not directly related to the assembly of authentic spliceosomes. Definitive proof must await reconstitution experiments with a highly purified system. However, given the very clear sequential relationship inherent in the observed kinetics of complex formation, and given that point mutations that reduce the rate of splicing also reduce the rate of forming $\alpha$, it is not unreasonable to postulate such a precursor-product model. If correct, it indicates a stepwise pathway for the assembly of mammalian spliceosomes, with snRNPs acting as subunits. A similar, stepwise scheme has been proposed recently for spliceosome assembly in the budding yeast, Sacharomyces cerevisiae (Pikielny et al. 1986). Although seemingly different in detail, the general similarity between the processes in yeast and mammals is quite striking, and probably reflects the antiquity and evolutionary conservation of the splicing machinery.

The analysis of mutant substrates indicated that the 


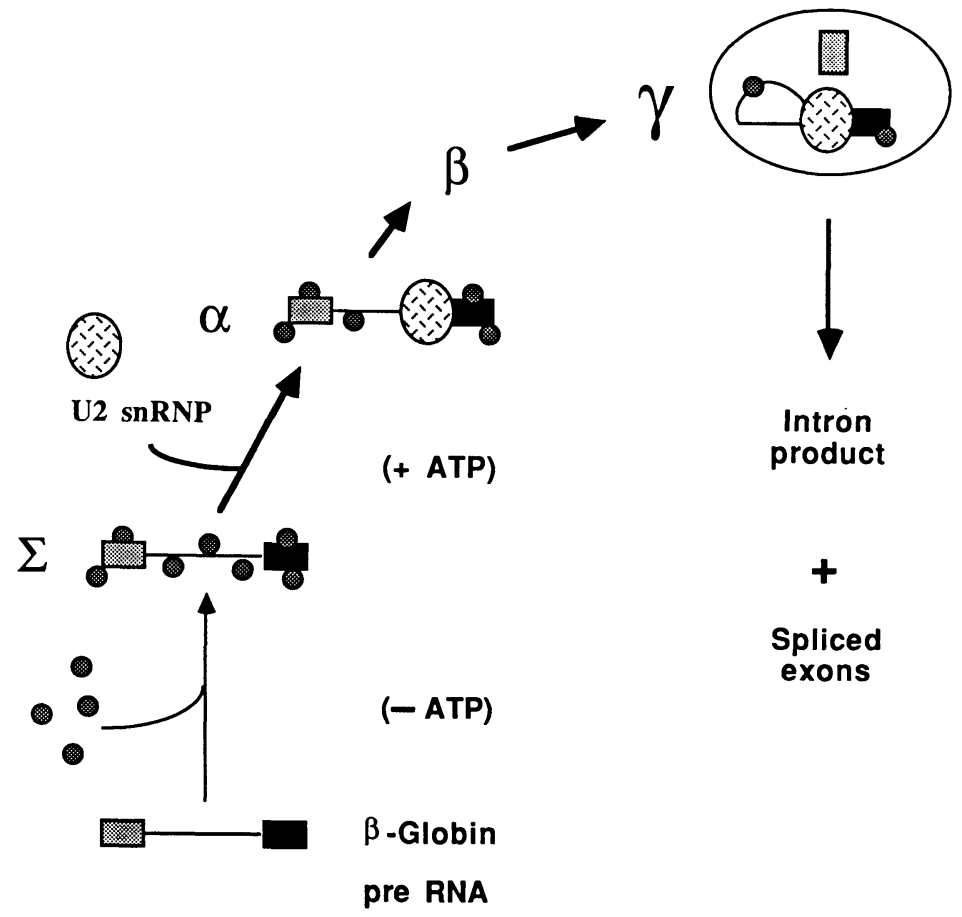

\begin{abstract}
Figure 7. A summary of the assembly of $\beta$-globin pre-RNA into separable complexes during an in vitro splicing reaction is illustrated schematically. Only the sigma complexes form in the absence of ATP. The persistence of sigma components in the subsequent ATP-dependent complexes is shown here by conjecture. So far, this has not been directly demonstrated by experimentation. The $\gamma$ complex is illustrated as a circle containing U2 snRNP. Both the $\beta$ and $\gamma$ complexes, as we will report elsewhere, contain other snRNPs in addition to U2.
\end{abstract}

$3^{\prime}$ splice site is likely to be the primary recognition site for the binding of splicing complexes. This is consistent with previous in vitro studies on splicing of the first intron of human $\beta$-globin. Using an assay based on protection from oligonucleotide-directed cleavage by RNase $\mathrm{H}$, it was shown that during an in vitro splicing reaction, the first detectable ATP-dependent complex forms on sequences upstream of the ${ }^{\prime}$ ' splice site (Ruskin and Green 1985b). Also, RNase T1 protection studies on an adenovirus pre-RNA substrate have shown that an ATPdependent, U2 snRNP complex assembles at the $3^{\prime}$ splice site early in the splicing reaction (Konarska and Sharp 1986). This complex almost certainly corresponds to the $\alpha$ complex described here. What we see as novel is the evidence for collaboration between the $5^{\prime}$ and $3^{\prime}$ splice sites in promoting the formation of $\alpha$ during spliceosome assembly. It is of particular interest that, at a very early stage of the assembly process, the $5^{\prime}$ splice site is able to facilitate the binding of a putative spliceosome subunit, the U2 snRNP, at the $3^{\prime}$ splice site. It is possible, then, that the rate of splicing of a particular intron is a blend of the efficiency of recognition of the sequences at the $3^{\prime}$ splice site by U2 snRNP, perhaps in conjunction with other factors, and the efficiency of interaction with components recognizing the $5^{\prime}$ splice site. At the moment, it is thought that a protein is responsible for recognition of the polypyrimidine tract and AG at the $3^{\prime}$ splice site (Tazi et al. 1986; Gerke and Steitz 1986). How U2 snRNP interacts with this protein during $\alpha$ formation and whether events at the $5^{\prime}$ splice site promote the binding of this protein or $\mathrm{U} 2$ snRNP remain to be determined.

The mechanism by which the $5^{\prime}$ splice site affects the rate of $\alpha$ complex binding could involve a trans-acting factor other than U2 snRNP. Such a factor might simul- taneously interact with $5^{\prime}$ splice site sequences and U2 snRNP to facilitate the formation of a stable $\alpha$ complex. An obvious candidate for this role is $\mathrm{Ul}$ snRNP, as previous studies have shown that it can interact, separately, with both $5^{\prime}$ splice site sequences and, albeit weakly, with a U2 snRNP particle (Black et al. 1985; Mattaj et al. 1986; Zhuang and Weiner 1986). If U1 snRNP is interacting with U2 snRNP in the reaction, either this pairing is unstable under our gel assay conditions or the interaction is only transient in nature. Northern hybridization analysis has shown that Ul snRNA is not present in the $\alpha$ complex at 1/100th the level of U2 snRNA. Another, alternative possibility is that the $\alpha$ complex is composed of a U2 snRNP particle that can itself recognize both the $5^{\prime}$ and $3^{\prime}$ splice sites. In this case, U2 snRNP may perhaps bind more avidly when contact is made simultaneously to both sequences. Distinguishing between these alternatives seems important and focuses future experimentation on establishing the potential role of $U 1$ snRNP in the generation of a $U 2$ snRNP-containing complex at the $3^{\prime}$ splice site.

\section{Note added during review}

A similar mobility retardation assay has also been used to analyze splicing complexes formed with a substrate RNA containing the leader 1 and 2 exons of adenovirus (Konarska and Sharp 1987). Two complexes, A and B, were resolved in this study. It is likely that the $\alpha$ complex formed with the $\beta$-globin substrate corresponds to the adenovirus A complex but these two complexes could differ in minor ways. Although it is not fully established, we believe that the equivalent complexes to the globins $\beta$ and $\gamma$ comigrated in the adenovirus B complex band in the previous study of Konarska and Sharp (1987). 


\section{Materials and methods}

In vitro splicing assays

Nuclear extracts were prepared from HeLa cells as described by Dignam et al. (1983). Splicing reactions were done at $30^{\circ} \mathrm{C}$, usually in a $10-\mu$ l volume, with the following standard conditions (final concentrations): $35 \%$ nuclear extract (vol/vol), 40 $\mathrm{mm} \mathrm{KCl}, 3 \mathrm{~mm} \mathrm{MgCl} 2,9 \mathrm{~mm} \mathrm{HEPES} \mathrm{NaOH}$ (pH 7.9), $12 \%$ glycerol (vol/vol), $70 \mu \mathrm{M}$ EDTA, $0.7 \mathrm{~mm}$ DTT, $1.5 \mathrm{~mm}$ ATP, $5 \mathrm{~mm}$ creatine $\mathrm{PO}_{4}, 1$ unit $/ \mu \mathrm{l}$ RNASIN, and $\sim 40 \mathrm{pg} / \mu \mathrm{l}$ pre-RNA $\left(10^{5}\right.$ $\mathrm{cpm} / \mathrm{ng}$.

Nuclear extract was always preincubated for $15 \mathrm{~min}$ at $30^{\circ} \mathrm{C}$ prior to the addition of pre-RNA. For subsequent RNA analysis the samples were treated with $200 \mu \mathrm{l}$ of proteinase $\mathrm{K}[100 \mu \mathrm{g}$ in $0.5 \mathrm{M} \mathrm{NH}_{4} \mathrm{OAc}$ (pH 7), $10 \mathrm{mM} \mathrm{MgCl} 2,0.1 \% \mathrm{SDS}$ (vol/vol), and $0.1 \mathrm{mM}$ EDTA], for $10 \mathrm{~min}$ at $30^{\circ} \mathrm{C}$, then extracted twice with phenol/chloroform $(1: 1)$, once with chloroform and ethanol precipitated together with $5 \mu \mathrm{g}$ of tRNA carrier. Ethanol pellets were washed with $70 \%$ ethanol, resuspended in formamide, heated at $65^{\circ} \mathrm{C}$ for $10 \mathrm{~min}$, and analyzed on $5 \%$ polyacrylamide/ $8 \mathrm{M}$ urea thin gels run in $1 \times$ TBE buffer. For the analysis of splicing complexes $3-\mu \mathrm{l}$ aliquots from the splicing reactions were loaded directly onto $4 \%$ native polyacrylamide gels and run in $50 \mathrm{~mm}$ Tris glycine buffer as described by Konarska and Sharp (1987).

\section{Elution of RNA from native gels}

Complexes separated on native polyacrylamide gels were electroblotted onto DEAE membrane (Schleicher \& Schuell NA45), in $50 \mathrm{~mm}$ Tris glycine buffer. The membrane was then cut into horizontal strips and the RNA eluted from each strip by incubation in BOB buffer [ $50 \%$ formamide (vol/vol), $20 \mathrm{mM}$ Tris $\mathrm{HCl}$ ( $\mathrm{pH} 7.5), 1 \mathrm{M} \mathrm{NaOAc}, 0.1 \% \mathrm{SDS}$, and $0.1 \mathrm{mM}$ EDTA], for 1 $\mathrm{hr}$ at $68^{\circ} \mathrm{C}$. Approximately $50 \%$ of the RNA was eluted from the filter by this procedure. Samples were spun for $5 \mathrm{~min}$ in a microfuge to pellet residual membrane fragments and then the aqueous material extracted once with phenol/chloroform $(1: 1)$ and once with chloroform, followed by ethanol precipitation together with $10 \mu \mathrm{g}$ tRNA carrier. The eluted RNAs were subsequently analyzed by electrophoresis in $5 \%$ polyacrylamide/ 8 $M$ urea gels run in $1 \times$ TBE buffer.

\section{Synthesis of pre-RNA substrate}

pre-RNA substrates were made by transcribing EcoRI-cut pBluescript- $\beta$-globin plasmids with T3 RNA polymerase (Stratagene Cloning Systems). Standard transcription conditions were (final concentrations): $40 \mathrm{mM}$ Tris $\mathrm{HCl}(\mathrm{pH} 7.9), 8 \mathrm{~mm}$ $\mathrm{MgCl}_{2}, 2 \mathrm{~mm}$ spermidine, $50 \mathrm{~mm} \mathrm{NaCl}, 10 \mathrm{~mm}$ DTT, $50 \mu \mathrm{M} \mathrm{A}$, $\mathrm{U}, \mathrm{C}$, and GTP, $1 \mathrm{~mm} \mathrm{5',5'} \mathrm{GpppG,} 50 \mu \mathrm{Ci}\left[\alpha^{-32}\right.$ P]UTP, 100 $\mu \mathrm{g} / \mathrm{ml}$ DNA template, 1 unit/ $\mu \mathrm{l}$ RNASIN, and 0.5 units/ $\mu \mathrm{l} \mathrm{T3}$ RNA polymerase.

Transcription reactions were performed for $2 \mathrm{hr}$ at $37^{\circ} \mathrm{C}$ and the full-length pre-RNAs subsequently isolated from $5 \%$ denaturing polyacrylamide gels, eluted as described by Grabowski et al. (1985), and further purified by chromatography on DEAE cellulose as described by Grabowski et al. (1984).

\section{Acknowledgments}

We are grateful to Drs. Paula Grabowski and Anders Virtanen for comments on the manuscript and for many helpful discussions. We also thank Dr. M. Aebi and Professor C. Weissmann for generously providing the $\beta$-globin point mutants used in this study and for the communication of their results prior to publication. A.I.L. acknowledges postdoctoral support from the Science and Engineering Research Council of Great Britain. This work was supported by a grant from the National Institutes of Health (No. GM34277) and partially by a National Cancer Institute core grant (No. CA14051) to P.A.S.

\section{References}

Aebi, M., H. Hornig, R.A. Padgett, J. Reiser, and C. Weissmann. 1986. Sequence requirements for splicing of higher eukaryotic nuclear pre-mRNA. Cell 47: 555-565.

Berget, S.M. and L. Robberson. 1986. U1, U2, and U4/U6 small nuclear ribonucleoproteins are required for in vitro splicing but not polyadenylation. Cell 46: 691-697.

Black, D.L., B. Chabot, and J.A. Steitz. 1985. U2 as well as U1 small nuclear ribonucleoproteins are involved in premessenger RNA splicing. Cell 42: 737-750.

Black, D.L. and J.A. Steitz. 1986. Pre-mRNA splicing in vitro requires intact U4/U6 small nuclear ribonucleoprotein. Cell 46: 697-704.

Brody, E. and J. Abelson. 1985. The "spliceosome": Yeast premessenger RNA associates with a $40 \mathrm{~S}$ complex in a splicing-dependent reaction. Science 228: 963-967.

Dignam, J.D., R.M. Lebovitz, and R.D. Roeder. 1983. Accurate transcription initiation by RNA polymerase II in a soluble extract from isolated mammalian nuclei. Nucleic Acids. Res. 11: 1475-1489.

Frendewey, D. and W. Keller. 1985. Stepwise assembly of a premRNA splicing complex requires U-snRNPs and specific intron sequences. Cell 42: 355-367.

Gerke, V. and J.A. Steitz. 1986. A protein associated with small nuclear ribonucleoprotein particles recognizes the 3 ' splice site of premessenger RNA. Cell 47: 973-984.

Grabowski, P.J. and P.A. Sharp. 1986. Affinity chromatography of splicing complexes: U2, U5, and U4 + U6 small nuclear ribonucleoprotein particles in the spliceosome. Science 233: 1294-1299.

Grabowski, P.J., R.A. Padgett, and P.A. Sharp. 1984. Messenger RNA splicing in vitro: An excised intervening sequence and a potential intermediate. Cell 37: 415-427.

Grabowski, P.J., S.R. Seiler, and P.A. Sharp. 1985. A multicomponent complex is involved in the splicing of messenger RNA precursors. Cell 42: 345-353.

Konarska, M.M. and P.A. Sharp. 1986. Electrophoretic separation of complexes involved in the splicing of precursors to mRNAs. Cell 46: 845-855.

Konarska, M.M. and P.A. Sharp. 1987. Interactions between small nuclear ribonucleoprotein particles in formation of spliceosomes. Cell (in press).

Krämer, A., W. Keller, B. Appel, and R. Lührmann. 1984. The 5' terminus of the RNA moiety of Ul small nuclear ribonucleoprotein particles is required for the splicing of messenger RNA precursors. Cell 38: 299-307.

Krainer, A.R. and T. Maniatis. 1985. Multiple factors including the small nuclear ribonucleoproteins $\mathrm{U} 1$ and $\mathrm{U} 2$ are necessary for pre-mRNA splicing in vitro. Cell 42: 725-736.

Mattaj, I.W., W.J. Habets, and W.J. van Venrooij. 1986. Monospecific antibodies reveal details of U2 snRNA structure and interaction between $\mathrm{U} 1$ and U2 snRNPs. EMBO I. 5: 9971002.

Newman, A.J., R.-J. Lin, S.-C. Cheng, and J. Abelson. 1985. Molecular consequences of specific intron mutations on yeast mRNA splicing in vivo and in vitro. Cell 42: 335-344.

Parker, R. and C. Guthrie. 1985. A point mutation in the conserved hexanucleotide at a yeast $5^{\prime}$ splice junction un- 
couples recognition, cleavage and ligation. Cell 41: 107118.

Perkins, K.K., H.M. Furneaux, and J. Hurwitz. 1986. RNA splicing products formed with isolated fractions for HeLa cells are associated with fast-sedimenting complexes. Proc. Natl. Acad. Sci. 83: 887-891.

Pikielny, C.W. and M. Rosbash. 1986. Specific small nuclear RNAs are associated with yeast spliceosomes. Cell 45: 869877.

Pikielny, C.W., B.C. Rymond, and M. Rosbash. 1986. Electrophoresis of ribonucleoproteins reveals an ordered assembly pathway of yeast splicing complexes. Nature 324: 341-345.

Reed, R. and T. Maniatis. 1985. Intron sequences involved in lariat formation during pre-mRNA splicing. Cell 41: 95105.

Ruskin, B. and M.R. Green. 1985a. An RNA processing activity that debranches RNA lariats. Science 229: 135-140.

Ruskin, B. and M.R. Green. 1985b. Specific and stable intronfactor interactions are established early during in vitro premRNA splicing. Cell 43: 131-142.

Tazi, J. C. Alibert, J. Temsamani, I. Reveillaud, G. Cathala, C. Brunel, and P. Jeanteur. 1986. A protein that specifically recognizes the $3^{\prime}$ splice site of mammalian pre-mRNA introns is associated with a small nuclear ribonucleoprotein. Cell 47: $755-766$.

Zhuang, Y. and A.M. Weiner. 1986. A compensatory base change in U1 snRNA suppresses a $5^{\prime}$ splice site mutation. Cell 46: 827-835. 


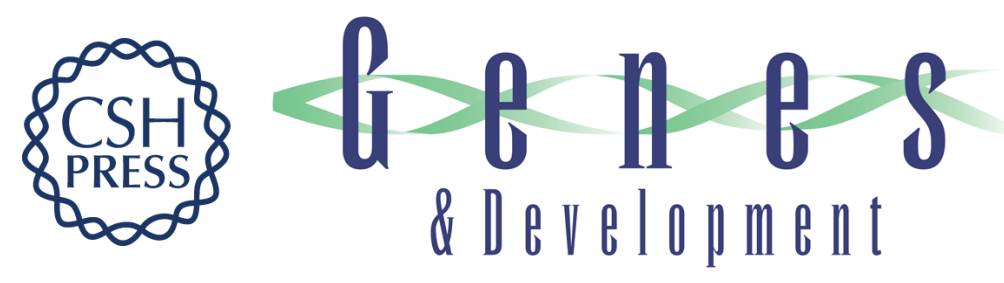

\section{A mutational analysis of spliceosome assembly: evidence for splice site collaboration during spliceosome formation.}

A I Lamond, M M Konarska and P A Sharp

Genes Dev. 1987, 1:

Access the most recent version at doi:10.1101/gad.1.6.532

References This article cites 25 articles, 4 of which can be accessed free at: http://genesdev.cshlp.org/content/1/6/532.full.html\#ref-list-1

License

Email Alerting

Receive free email alerts when new articles cite this article - sign up in the box at the top Service right corner of the article or click here.

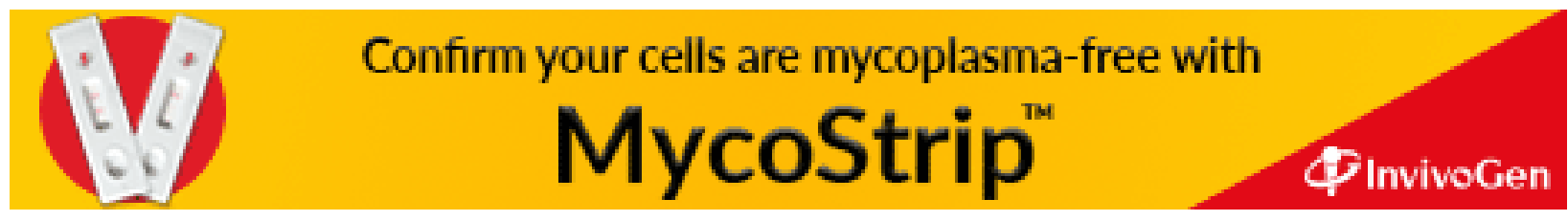

